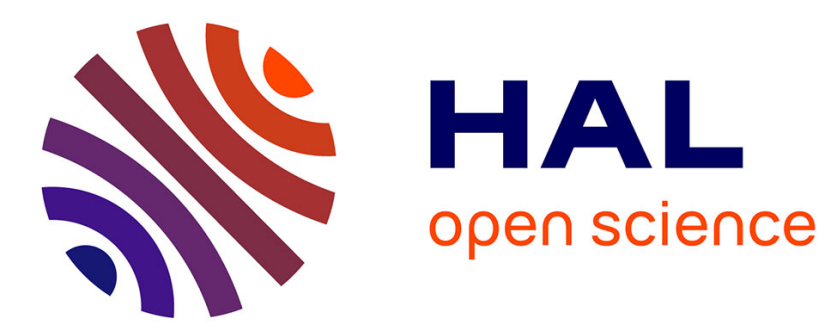

\title{
3D Digital Volume Correlation of Synchrotron Radiation Laminography images of ductile crack initiation: An initial feasibility study
}

\author{
Thilo F. Morgeneyer, Lukas Helfen, Hazem Mubarak, François Hild
}

\section{To cite this version:}

Thilo F. Morgeneyer, Lukas Helfen, Hazem Mubarak, François Hild. 3D Digital Volume Correlation of Synchrotron Radiation Laminography images of ductile crack initiation: An initial feasibility study. Experimental Mechanics, 2013, 53, pp.543-556. 10.1007/s11340-012-9660-y . hal-00848726

\author{
HAL Id: hal-00848726 \\ https://hal.science/hal-00848726
}

Submitted on 28 Jul 2013

HAL is a multi-disciplinary open access archive for the deposit and dissemination of scientific research documents, whether they are published or not. The documents may come from teaching and research institutions in France or abroad, or from public or private research centers.
L'archive ouverte pluridisciplinaire $\mathbf{H A L}$, est destinée au dépôt et à la diffusion de documents scientifiques de niveau recherche, publiés ou non, émanant des établissements d'enseignement et de recherche français ou étrangers, des laboratoires publics ou privés. 


\title{
3D Digital Volume Correlation of Synchrotron \\ Radiation Laminography images of ductile
} crack initiation: An initial feasibility study

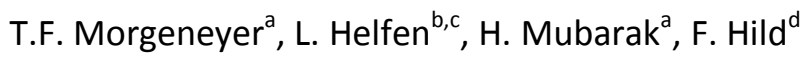 \\ ${ }^{a}$ Mines ParisTech, Centre des Matériaux, CNRS UMR 7633, BP87 91003 Evry Cedex, \\ France
}

${ }^{b}$ ANKA/Institute for Synchrotron Radiation, Karlsruhe Institute of Technology (KIT), D76131 Karlsruhe, Germany

${ }^{c}$ European Synchrotron Radiation Facility (ESRF), BP 220, F-38043 Grenoble cedex, France

${ }^{d}$ LMT-Cachan, ENS Cachan/CNRS/UPMC/PRES UniverSud Paris, 61 avenue du Président Wilson, 94235 Cachan Cedex, France

Abstract

A feasibility study of measuring 3D displacement fields in the bulk during ductile crack initiation via combined Synchrotron Radiation Computed Laminography (SRCL) and Digital Volume Correlation (DVC) is performed. In contrast to Tomography, SRCL is a technique that is particularly adapted to obtain in 3D reconstructed volumes of objects that are laterally extended (i.e., in 2 directions) and thin in the third direction, i.e. sheet-like objects. In-situ laminography data of an initiating crack ahead of a machined notch are used with a voxel size of $0.7 \mu \mathrm{m}$. The natural contrast of the observed 2XXX Al-alloy caused by intermetallic particles and initial 
porosity is used to measure displacement fields via a global DVC technique assuming a continuous displacement field. An initial performance study is carried out on data of the same undeformed material but after a substantial shift of the laminography rotation axis with respect to the imaged specimen. Volume correlations between different loading steps provide displacement fields that are qualitatively consistent with the remote loading conditions. Computed strain fields display a strain concentration close to the notch tip.

Aluminium alloy; Digital Volume Correlation; ductile fracture; displacement field; resolution; strain field; Synchrotron Radiation Laminography;

\section{Introduction}

Fracture toughness of ductile materials is a critical design parameter and needs to be improved continuously to reduce the weight of structures for transportation applications [1]. Recent progress in aluminium alloy composition [2] and use of novel joining techniques such as friction stir welding [3] allows aluminium alloys to remain candidate materials for future aircraft generations. Despite the research that has gone into the understanding of ductile fracture, fundamental aspects of fracture at low levels of stress triaxiality are still poorly understood and, e.g., the physical origin of the flat to slant crack transition of cracks is not fully known [1,4-6].

In order to gain further insight into damage mechanisms of metallic materials, in-situ tomography tests may be carried out [7-9] or arrested cracks may be investigated via tomography [6]. For the study of ductile crack initiation and propagation a drawback of the tomography technique is the small match stick-like specimen shapes with cross sections of the order of $1 \times 1 \mathrm{~mm}^{2}$. However, the plastic zone sizes that may develop in structures in service made of ductile sheet material may reach sizes of millimetres or even centimetres with these boundary conditions. With the recent progress in 
synchrotron radiation laminography [10-12] it has become possible to observe objects that are plate-like, i.e. extended in 2 directions and thin in the $3^{\text {rd }}$ one. Via this technique the damage kinetics in a carbon fibre reinforced (CFR) composite has been observed insitu [13]. Ductile crack initiation and propagation in a $2139 \mathrm{Al}$ alloy has been studied for the first time in 3D and in situ [14] with thin $(1 \mathrm{~mm})$ sheet material with boundary conditions close to those of structures in service and close to standard mechanical tests to assess the tearing resistance. The obtained data will be used in the present study.

For the measurement of strain fields during loading of samples / components made of engineering materials the use of Digital Image Correlation (DIC) techniques [15] is now widely practiced. These techniques are based on the registration of images containing a random texture on specimen surfaces. The DIC techniques are used in 2D or 3D situations for the case of stereo correlation. For measurement of 3D displacement fields in the bulk using data obtained, e.g., by in-situ 3D tomography, Digital Volume Correlation (DVC) has been developed [16-21]. DVC is seen to provide better results in terms of measurement uncertainty than 3D particle tracking techniques $[22,23]$. In DVC (as in DIC) different approaches are used, namely, local techniques (e.g. [16-21]) do not require the displacement fields to be continuous from interrogation volumes to interrogation volumes, while global techniques generally assume continuous displacement fields [24]. However, extensions have also been proposed to analyse discontinuous displacements across cracked surfaces $[25,26]$. The technique in its standard version has been successfully applied to the displacement field measurement of a polypropylene foam in compression. The used 3D images had been obtained by SRCT with a voxel size of $\sim 5 \mu \mathrm{m}$. This approach has been applied to the 3D displacement field measurement during fatigue crack propagation in nodular graphite cast iron [27]. The used SRCT images had a voxel size of $\sim 5 \mu \mathrm{m}$. The measured displacement fields could successfully be used to calculate stress intensity factor values. 
In the present study the global DVC approach based on 8-noded cube elements with trilinear shape functions $[24,27]$ will be used to assess the feasibility of the measurement of displacement fields during ductile crack initiation in an industrial $2 \mathrm{XXX}$ aluminium alloy [28] observed by 3D in-situ SRCL. In the first part of the study a performance assessment is carried out for 2 scans of undeformed material for which the scan rotation centre has been shifted. The resolution is determined for different element sizes. Second, 3D laminography images taken at different loading steps are used for correlation purposes. An updated correlation method is used as well as a direct correlation using cumulated displacement results as an initial guess. The correlation residuals are assessed. Some initial results are given in terms of displacement and strain fields.

\section{Experiment}

\section{Material}

The material used for the present study is an AA2139 aluminium alloy for aerospace applications in ductile T3 condition. The mechanical properties of the material in terms of stress strain curves and ductile tearing curves are given in Reference [28]. The intermetallic content has been determined to be $\sim 0.45$ vol\% and the initial void volume fraction $\sim 0.34 \%$. The distribution of pores and particles has been assessed on tomographic data via Feret dimensions of 3D Voronoi cells around pores and particles. An isotropic average value of the Voronoi cell dimensions of $\sim 25 \mu \mathrm{m}$ has been obtained. The sheet material has been provided with 3.2-mm thickness and has subsequently been machined symmetrically to $1-\mathrm{mm}$ thickness. The material processing directions are the L-(rolling) direction, T-(transverse) direction and S-(short transverse) direction. 


\section{Mechanical In-situ test}

The specimen geometry of the flat notched specimen is shown in Figure 1 [14]. The 1$\mathrm{mm}$ thick specimen (60- $\mathrm{mm}$ in width and $70-\mathrm{mm}$ in height) contains a notch that has been machined by EDM resulting in a radius of $0.15 \mathrm{~mm}$. The initial notch length $(a)$ to width $(W)$ ratio is $a / W=0.6$. The loading has been applied via opening the notch mouth with a displacement controlled 2-screw opening device, without measuring the load level. Stepwise loading has been applied between each laminography scan. The applied total crack mouth opening displacement (CMOD) for the steps relevant to this work were: step $1 \rightarrow \mathrm{CMOD}=0.5 \mathrm{~mm}$; step $2 \rightarrow \mathrm{CMOD}=0.75 \mathrm{~mm}$; step $3 \rightarrow \mathrm{CMOD}=$ $1.0 \mathrm{~mm}$. The material is assumed to deform plastically from the first loading step onwards (it will be proven hereafter). Loading was performed in the T-L configuration. An anti-buckling device (not shown here) has been mounted around the specimen, leaving a window for the synchrotron $\mathrm{x}$-ray laminography close to the notch to prevent the thin sheet from buckling in the compressive zone. The region of interest for the scan was close to the notch.

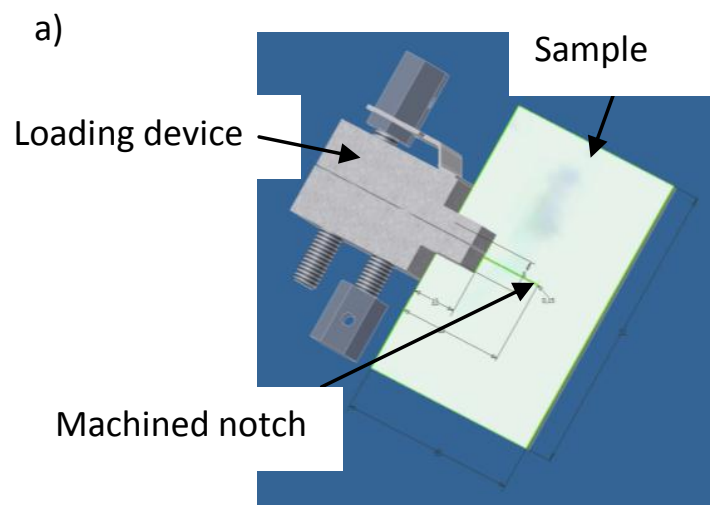

b)

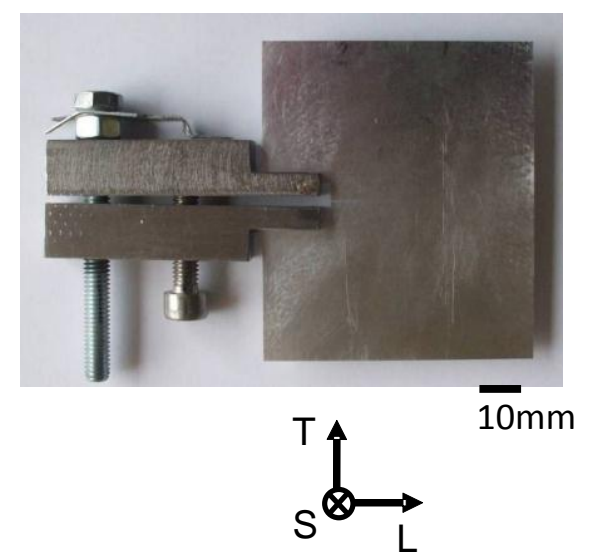

Figure 1: a) Sketch of the in-situ loading setup with 2-screw loading device and specimen with dimensions $60 \times 70 \times 1 \mathrm{~mm}^{3}$. The notch length was $36 \mathrm{~mm}$ and its radius $0.15 \mathrm{~mm}$. The anti-buckling frame is not shown. b) Photograph of the setup 


\section{Laminography / 3D image details}

SR-CT is particularly adapted to imaging of one-dimensionally elongated objects (i.e., beam-like samples) that stay in the field of view of the detector system under rotation. In contrast, SR-CL [29] is optimised towards imaging of laterally extended (i.e., plate or sheet-like) specimens. For laminography, the rotation axis of the specimen is inclined at an angle of $\theta<90^{\circ}$ with respect to the beam direction (where $\theta=90^{\circ}$ corresponds to the case of (T). The specimens are typically turned around the normal vector of the sheet plane (see Figure 2).

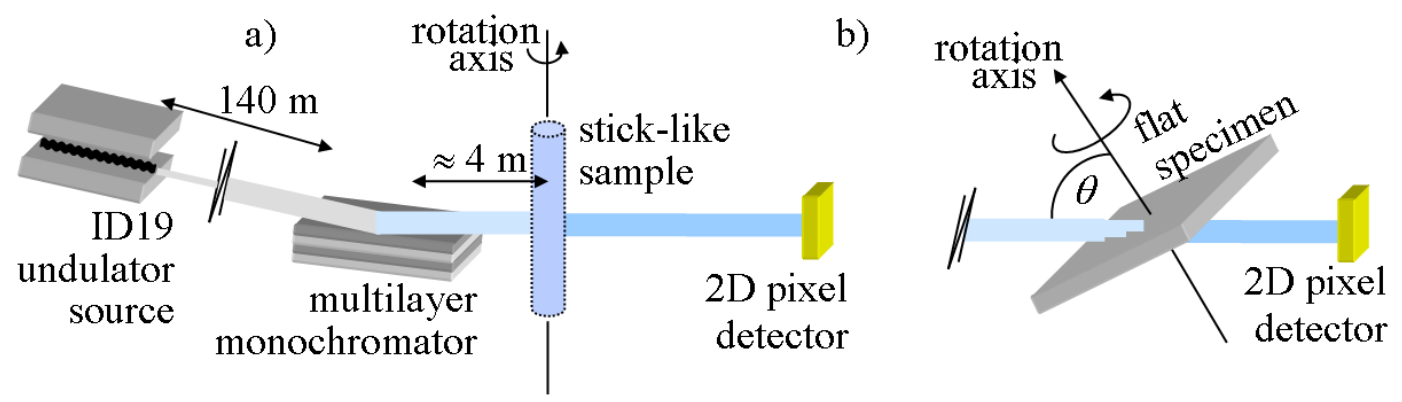

Figure 2: Schematic views of a typical CT setup (a) in comparison to the CL setup (b) at synchrotron beamlines with parallel-beam geometry.

For plate-like specimens this enables for a relatively constant average $\mathrm{X}$-ray transmission over the entire scanning range of $360^{\circ}$, which in turn allows for the acquisition of reliable projection. Using a filtered-backprojection algorithm [10], a 3D image of the imaged specimen around the rotation axis is reconstructed from the 2D projections.

Although the sampling of the 3D Fourier domain of the specimen is incomplete [10], which leads to imaging artefacts, the latter ones are often less disruptive than those produced by (limited-angle) CT [30,31]. Exploiting phase-contrast imaging based on freespace propagation of the wavefield $[32,33]$ or on grating interferometry $[34,35]$, new application fields related to weakly absorbing / weakly contrasted structures are opening up $[35,36]$. In the present study particular attention will be paid to the influence of these artefacts on the correlation resolution / performance. 
Imaging was performed on KIT laminography instrument installed at beamline ID19 [37] of the European Synchrotron Radiation Facility (ESRF, Grenoble, France). An inclination angle of the specimen rotation axis of about $25^{\circ}$ with respect to the beam normal $(\theta$ $\approx 65^{\circ}$ ) was chosen as well as a monochromatic beam of $25 \mathrm{keV}$-ray energy [14]. The multilayer monochromator employed for imaging has a very inhomogeneous beam profile [38] and therefore is prone to introducing further artefacts (i.e., so-called 'ringartefacts') that can also be encountered in CT images [39]. Volumes were reconstructed from 1,500 angularly equidistant radiographs; the exposure time of each projection was $250 \mathrm{~ms}$. The scanned region was $\sim 1 \mathrm{~mm}^{3}$ in volume with a voxel size of $0.7 \mu \mathrm{m}$. The minimum specimen to detector distance was $70 \mathrm{~mm}$ leading to relatively strong edge enhancement [40] due to phase contrast. The resulting strongly contrasted edges are also expected to contribute to laminography artefacts typical for incomplete sampling. For easier data handling, all 3D images consisting of 32-bit floating point values were converted into 8-bit grey level 3D images using the same linear dependence. As the same affine transformation is performed after the reconstruction the grey value levels between the images were comparable.

The final reconstructed volumes have a size of 2040 × 2040 × 2040 voxels. However, only the voxels where all projections contribute to the reconstruction exhibit all the directional information available and show similar noise statistics. This means that, e.g., the corners of the volumes can be expected not to produce consistent results in subsequent analysis steps such as DVC applied herein. In addition, some part of the volume in the through thickness direction of the sample consists of void space (i.e., air) as the thickness corresponds to only 1500 voxels. The influence of the location of the region of interest (ROI) and its quality on the correlation results will also be studied herein. Therefore, the specimen was imaged before and after translation by a given 
macroscopic displacement with respect to the rotation axis while ensuring that some part is contained in both reconstructed volumes.

\section{Digital Volume Correlation}

The digital volume correlation method used herein is very similar to the technique described in [24]. It consists in comparing pairs of reconstructed volumes assuming the conservation of grey levels. Let $f(\underline{x})$ denote the 3D image in the reference configuration, i.e. a 3D grey-level valued matrix, and $g(\underline{x})$ that in the deformed configuration. If the displacement field $\underline{u}(\underline{x})$ that relates both images is found

$f(\underline{x}) \cong g(\underline{x}+\underline{u}(\underline{x}))$

Here a global technique is used assuming continuous displacement fields similar to finite element calculations [41]. Using a specific displacement basis $\underline{\varphi}_{i}(\underline{x})$, the displacement field is decomposed as

$\underline{u}(\underline{x})=\sum_{i} a_{i} \underline{\varphi}_{i}(\underline{x})$

The grey level conservation (1) is considered in its weak form. The objective functional $\Phi^{2}$ needs to be minimized

$\Phi^{2}(\{\mathbf{a}\})=\int_{R O I}\left[f(\underline{x})-g\left(\underline{x}+a_{i} \underline{\varphi_{i}}(\underline{x})\right)\right]^{2} d \underline{x}$

with respect to the unknown degrees of freedom $a_{i}$ gathered in vector $\{\mathbf{a}\}$. This nonlinear minimization procedure is carried out via a modified Newton scheme in which the linearized functional $\Phi_{\text {lin }}^{2}$ is minimised iteratively when a finite-element formulation is assumed (i.e., the functional is evaluated over a discretization consisting of various elements $\Omega_{e}$ ) 
$\Phi_{\text {lin }}^{2}(\{\delta \mathbf{a}\})=\sum_{e} \int_{\Omega_{e}}\left[f(\underline{x})-\hat{g}(\underline{x})-\delta a_{i}^{e} \underline{N}_{i}(\underline{x}) \cdot \underline{\nabla} f(\underline{x})\right]^{2} d \underline{x}$

with respect to the corrections $\{\delta \mathbf{a}\}$ of vector $\{\mathbf{a}\}$ gathering all nodal displacements $\delta a_{i}^{e}$, where $\hat{g}$ is the current estimate of the 3D image in the deformed configuration corrected by the displacement field. The optimisation of the quadratic functional (4) leads to the following linear system

$[\mathbf{M}]\{\delta \mathbf{a}\}=\{\mathbf{b}\}$

with the elementary matrix and vector defined by

$$
\begin{aligned}
& M_{i j}^{e}=\int_{\Omega_{e}}\left(\underline{\nabla} f \cdot \underline{N}_{i}\right)(\underline{x})\left(\underline{\nabla f} \cdot \underline{N}_{j}\right)(\underline{x}) d \underline{x} \\
& b_{i}^{e}=\int_{\Omega_{e}}[f(\underline{x})-\hat{g}(\underline{x})]\left(\underline{\nabla} f . \underline{N}_{i}\right)(\underline{x}) d \underline{x}
\end{aligned}
$$

where $\hat{g}(\underline{x})=g\left(\underline{x}+\underline{u}^{i}(\underline{x})\right)$, and $\underline{u}^{i}$ is the estimate of the displacement field at iteration $i$. A multiscale approach is implemented to allow large displacements to be measured [41]. The convergence of the iteration scheme is measured in terms of the mean displacement increment between two consecutive iterations. When small displacements are sought, typical values are $10^{-4}$ voxel. When (very) large displacements occur, this value is increased tenfold.

In a finite element based DVC approach, as is the case in the present analysis with C8 elements (i.e., 8-noded cubes with trilinear displacement interpolation), the only parameter the user has to choose is the element size $\ell$ (i.e., each element contains $\ell^{3}$ voxels). With a structured mesh, this size is identical everywhere. The choice of the element size will be guided by the evaluation of measurement uncertainties in the next section. It will be shown that 16-voxel elements a good compromise between measurement uncertainty and spatial resolution. 
To measure large displacements, which will occur in the present case, the following steps are considered in addition to the multiscale approach. A first run is performed in which, for a series of reconstructed volumes, the reference configuration is updated for each new displacement measurement, namely, the scan in the deformed configuration of step $n$ becomes the reference scan of step $n+1$ (i.e., a purely incremental assessment). To get the total displacement field, the incremental displacement fields are cumulated. Since the various ROIs used in the previous approach do not necessarily coincide, the measured displacement increments are interpolated by using the chosen shape functions so that a unique mesh is considered, namely, that of the ROI in the reference configuration of the first step. A Lagrangian estimate of the displacement field is obtained by following this procedure. The advantage of such an analysis is that very large displacements can be measured. The drawback is that measurement uncertainties are cumulated. Therefore it is proposed to use this first estimate of the measured displacement as initialization of a new analysis in which the reference scan is always the same. This final procedure just consists in small corrections to the initial guess.

\section{Correlation residuals}

In order to assess the quality of each correlation the residual needs to be assessed. It is a local estimate, i.e. at each voxel, and also a global one. The (global) correlation residual $\eta$ is defined as the mean absolute difference between the reference and the corrected deformed image scaled by the dynamic range of the reference image $\Delta f$ (in the case of 8-bit images this dynamic range of the image is typically 256)

$$
\eta=\frac{1}{|R O I|} \int_{R O I} \frac{|f(\underline{x})-g(\underline{x}+\underline{u}(\underline{x}))|}{\Delta f} d \underline{x}
$$

The value at convergence reaches levels of the order of a few percent when the registration is successful [41]. One of the reasons for which the residuals never tend to 
zero is associated with the fact that the grey level conservation is never strictly satisfied because of acquisition noise and reconstruction artefacts. One source of noise is linked to artefacts on the optical path such as defects on the monochromator, scintillator or detector that result in ring artefacts. The beam intensity may also change between several scans resulting in a change of average grey levels. As for laminography the 3D Fourier domain of the specimen is not sampled completely, additional artefacts arise compared to tomography [10].

In the analyses of experimental scans, three different correlation residuals will be compared. First the raw difference $f(\underline{x})-g(\underline{x})$, or initial discrepancy, which is given when no displacement (i.e., $\underline{u}(\underline{x})=\underline{0}$ ) is assumed. Second, the difference between the reference volume and the deformed volume for which a rigid body translation (i.e., $\left.\underline{u}(\underline{x})=\underline{u}_{0}\right)$ is assumed $f(\underline{x})-g\left(\underline{x}+\underline{u}_{0}\right)$. This is the very first step of the correlation analysis to reposition the $\mathrm{ROI}$ of the volume in the deformed configuration with respect to the ROI in the reference configuration. Last, the correlation residual at the end of the correlation procedure $f(\underline{x})-g(\underline{x}+\underline{u}(\underline{x}))$. Except when displacement and strain amplitudes are very small, the initial residual is expected to be higher than that after a first rigid translation correction, the latter being itself larger than that at convergence. If this condition is not satisfied, the user should pay attention to the results as they are likely to correspond to an unconverged situation. 


\section{Results}

\section{Performance assessment}

To assess the displacement and strain resolutions ${ }^{1}$ of the DVC technique that are linked to the noise and artefacts of the laminography technique an analysis of 2 scans of the same ROI of the undeformed specimen has been carried out.

(a) Machined notch

(b) Void (used as reference for ROI

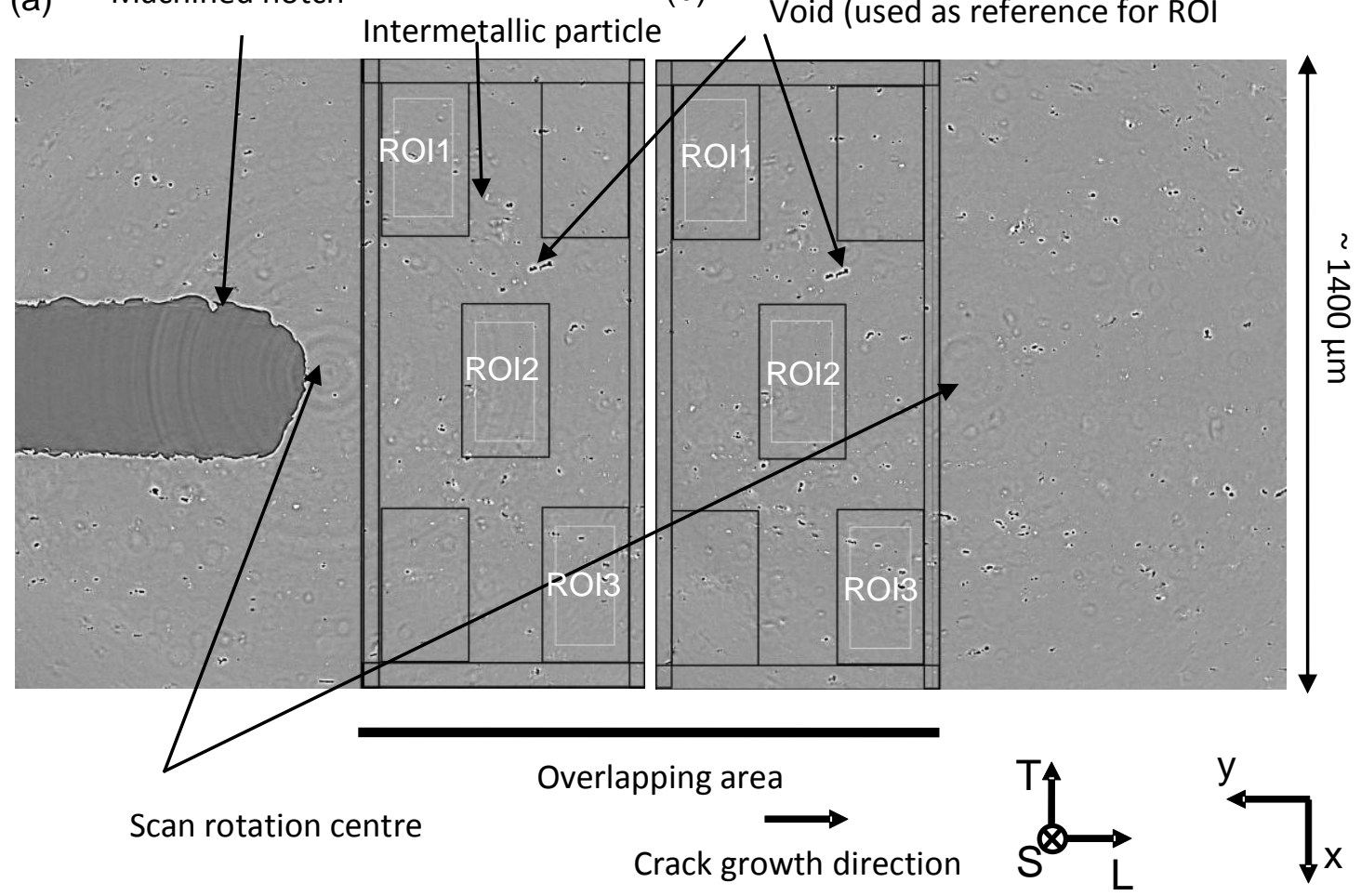

Figure 3: 2D section of reconstructed laminography scans at mid thickness showing the location of the extracted volumes $(500 \times 280 \times 600$ voxels $)$ in black and ROls ( $384 \times 192 \times 448$ voxels ) in white for a) the initial scan (0a) of undeformed material around the notch and $\mathrm{b}$ ) the scan $(\mathrm{Ob})$ after a shift of the scan centre by $0.8 \mathrm{~mm} /$ rigidbody-motion of the specimen.

\footnotetext{
${ }^{1}$ The resolution of a measuring system is the 'smallest change in a quantity being measured that causes a perceptible change in the corresponding indication' [42]. With this definition, high resolution levels do not allow small fluctuations to be measured.
} 
The location of the rotation axis, however, has been moved by $\sim 800 \mu \mathrm{m}$ (this procedure will definitely introduce more noise and artefacts than scanning the identical location twice without shifting the rotation axis). Figure 3 shows 2D sections at mid-thickness of the 2 scans of the undeformed material with shifted scan centre. The locations of the regions of interest for which correlations are performed are also shown.

Figure 4 shows 2D sections of the two scans of the undeformed material in the through thickness plane normal to the subsequent crack propagation direction. In this through thickness direction 3 different regions have been assessed, namely, left - centre - right.

(a) scan 0a

Left

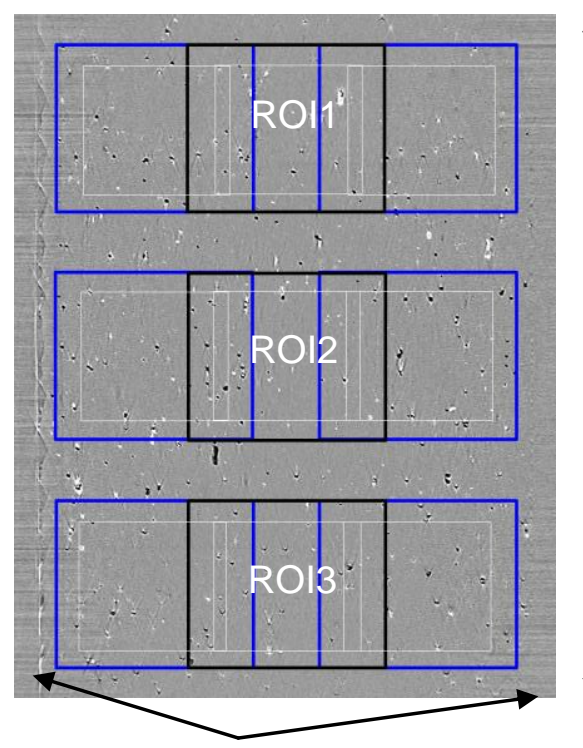

Specimen border (b) scan $0 \mathrm{~b}$

Left Centre Right

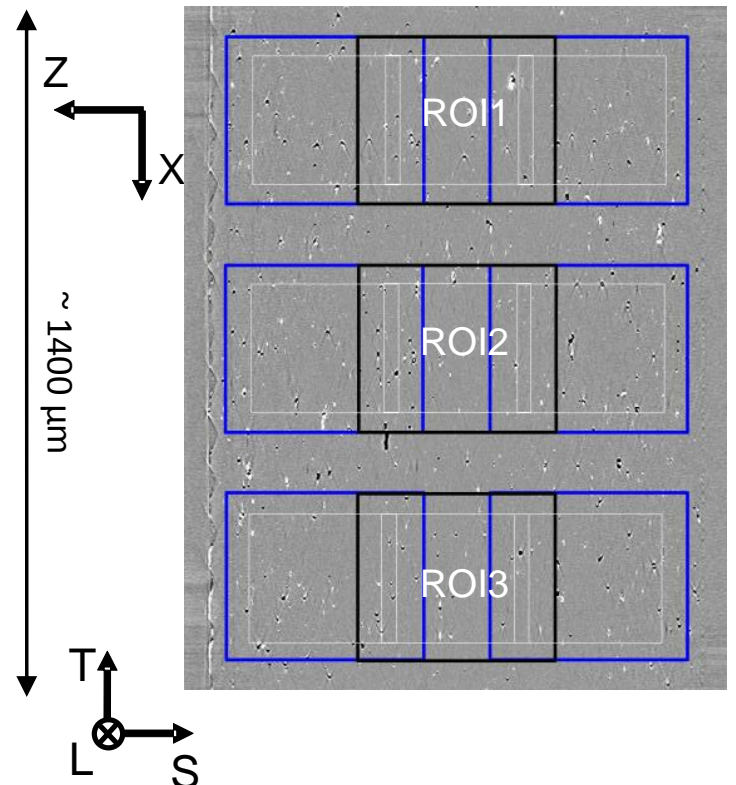

Figure 4: 2D sections of reconstructed laminography scans in the through thickness plane (containing the reference feature) showing the locations of the noise assessment of the undeformed material for a) scan $0 a$ and b) scan $0 b$, Thick lines indicate numerically extracted volumes. Extracted volumes left and right are shown in blue. Thin lines indicate ROIs for correlations (ROI1 and ROI3 lie in another geometrical plane than that shown). 
The correlations have been carried out with an element size $\ell=16$ voxels and a convergence criterion of $10^{-4}$ voxel in terms of mean incremental displacement. Since a finite-element based global approach is used, the spatial resolution is equal to twice the element size $\ell$ for inner nodes since they are shared by $2^{3}$ elements.

\section{Correlation residuals}

Figure 5 shows the three values of the correlation residuals for the nine analyzed ROls. In all the analyzed cases, the initial discrepancy (mean value: $4.8 \%$ ) is significantly higher than the final discrepancy (mean value: 4.2\%). The discrepancy after translation corrections has a mean value ( $4.4 \%)$ that is close to the final value. This result indicates that the main correction is a rigid body translation. This is to be expected from the construction of scans $0 \mathrm{a}$ and $\mathrm{Ob}$. The mean level of the final discrepancies is very important to assess, since it will be the reference when subsequent correlations are run. Any result leading to a final discrepancy of the order of $4.2 \pm 0.3 \%$ can be deemed trustworthy. 


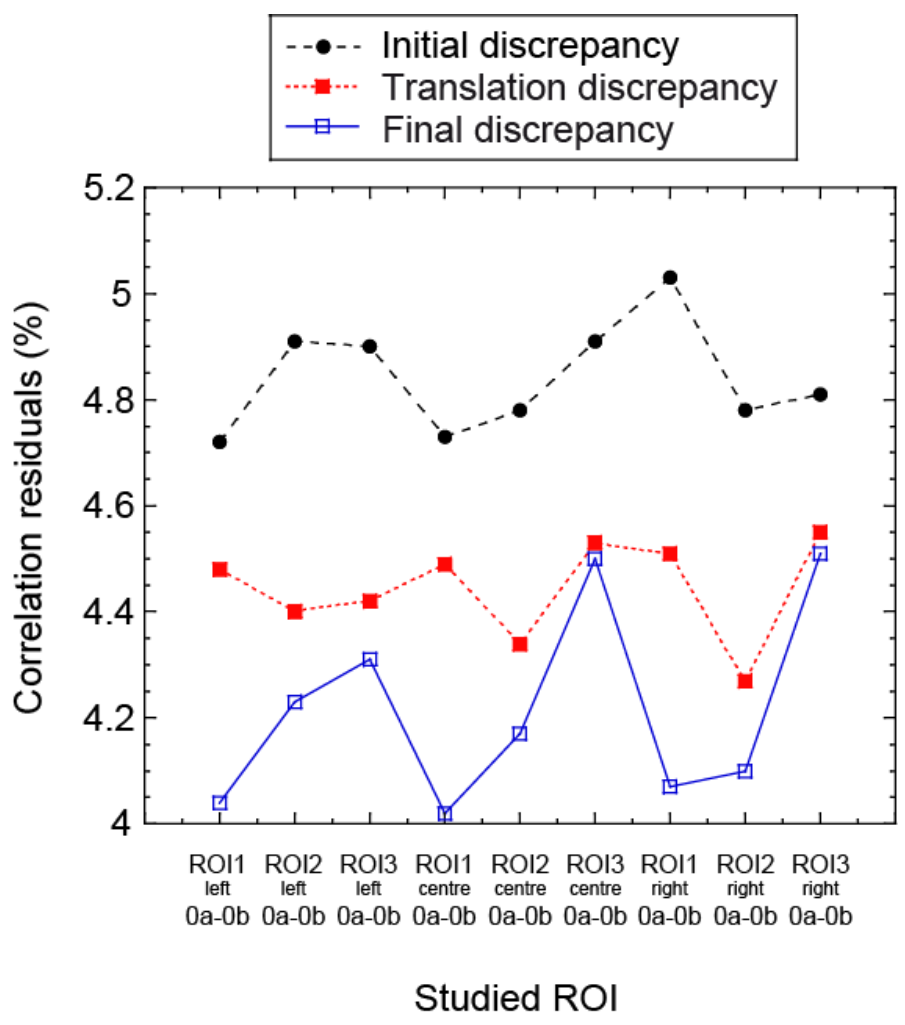

Figure 5: Three correlation residuals as functions of the studied ROIs for the rigid-bodymotion/resolution analysis ( $\ell=16$ voxels).

\section{Resolutions}

The displacement resolution is estimated as follows. The measured displacement field is interpolated by a linear field of all the space variables. When using this procedure, small rotations are accounted for. Since the exact value of the rigid body motion prescribed to the sample is unknown, the resolution is estimated from the difference between the measured and interpolated displacement fields. The RMS average of the difference between the measured and interpolated displacement field gives an estimate of the standard displacement resolution $\sigma_{u}$ for each displacement component. Figure 6 shows the results for the different ROls. First, the smallest value of the resolution is of the order of 0.3 voxel. This level is high compared with those observed in CT conditions (i.e., 0.1 voxel or less for the same element size $[43,44]$. Second, the displacement 
uncertainty in the through-thickness (z)-direction (i.e., along the rotation axis) appears to be higher than in the two in-plane directions. If this is not specific to the material/scanning conditions, it can be explained by the missing spatial frequencies and reduced resolution of laminographic scans along the rotation axis. Last, the ROI2s (left, centre, right) lead to systematically lower displacement resolutions as compared to ROI1s and ROI3s. This result was expected, namely, only the voxels where all projections contribute to the reconstruction exhibit all the directional information available and show similar noise statistics.

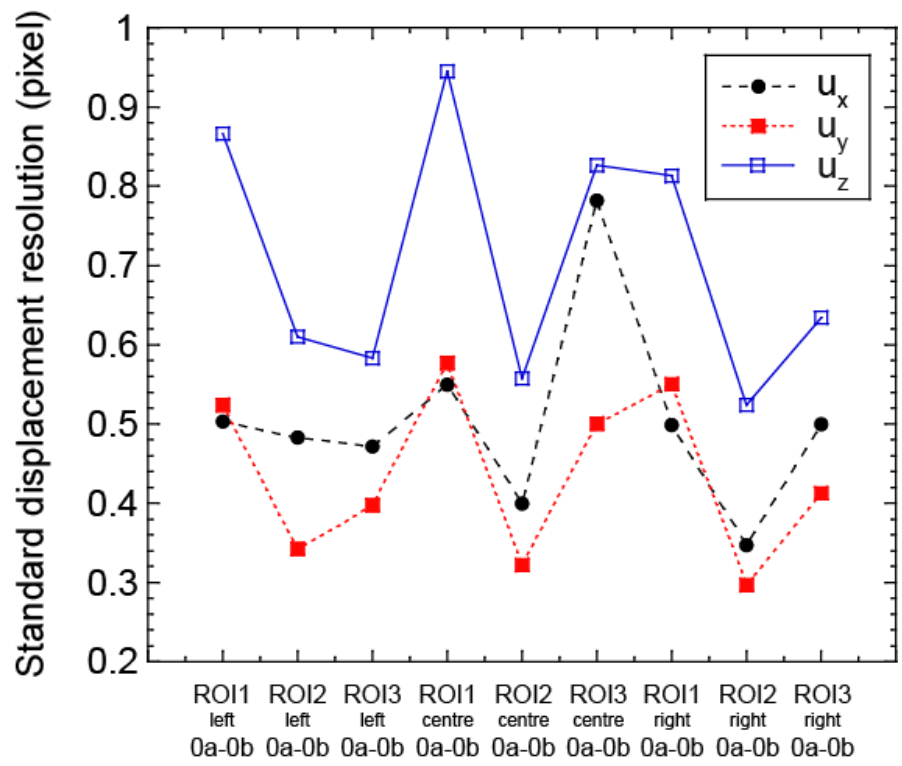

Studied ROI

Figure 6: Standard displacement resolutions along the three directions as functions of the studied ROI for the rigid-body-motion/resolution analysis ( $\ell=16$ voxels).

Let us note that these conclusions are a priori only valid for the studied texture, which is very difficult since the volume fraction of markers is very small. In particular, to compare the metrological performances to be expected with SRLC compared with CT, the same texture should be compared. Some additional studies are therefore needed to confirm the present result and trend, in particular with different materials (i.e. textures). 
By using the same measured displacement field, the strain resolution is estimated as follows. First, the mean displacement gradient is computed in each element by using the interpolation function of C8 elements [43]. The mean value and the standard deviation of each normal strain components are then assessed over each analyzed ROI. The mean value is one order of magnitude less than the standard deviation. Consequently, only the latter is reported herein. Figure 7 shows the results obtained for the 9 ROls. The same trends as those observed for the displacement resolution are found, in particular concerning the lower levels for the ROI2s. The minimum value of the strain resolution is of the order of $1 \%$. Consequently, only large strain levels can be evaluated under the present conditions.

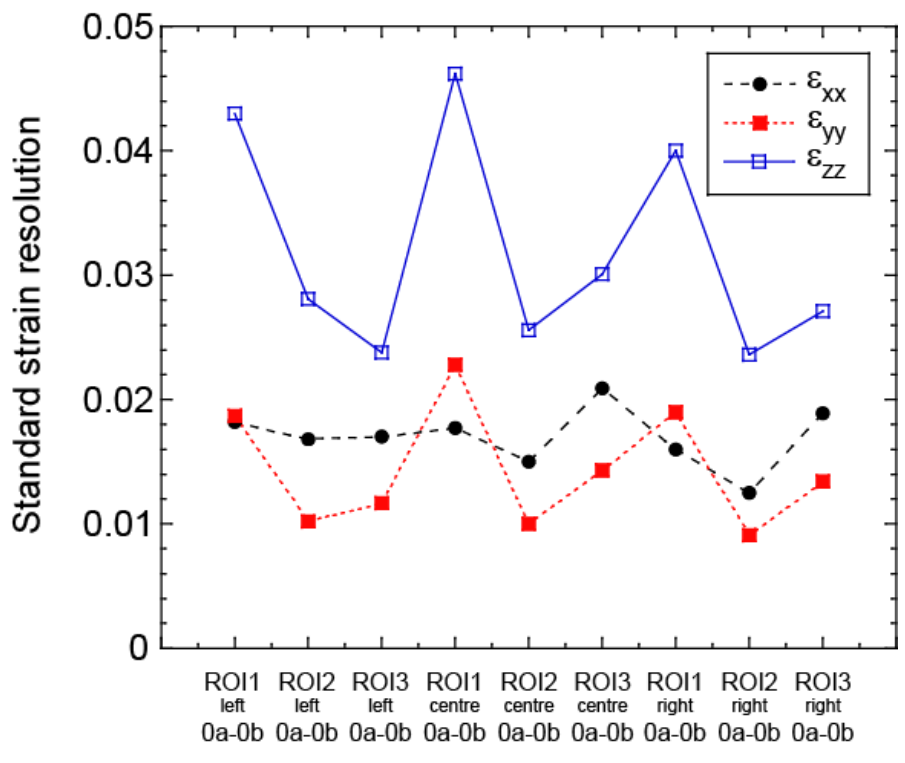

Studied ROI

Figure 7: Standard strain resolutions along the three directions as functions of the studied ROI for the rigid-body-motion/resolution analysis ( $\ell=16$ voxels).

The standard displacement $\sigma_{u}$ and strain $\sigma_{\varepsilon}$ resolutions are related by [44]

$\sigma_{\varepsilon}=\alpha \frac{\sigma_{u}}{\ell}$ 
where $\alpha$ is a dimensionless constant that depends on the type of correlation algorithm (i.e., local or global [45]). Figure 8 shows the correlation between the standard strain resolution $\sigma_{\varepsilon}$ and the normalized displacement resolution $\sigma_{u} / \ell$ for all the data of Figures 6 and 7. A linear interpolation of the results leads to a value of 0.63 for constant $\alpha$.

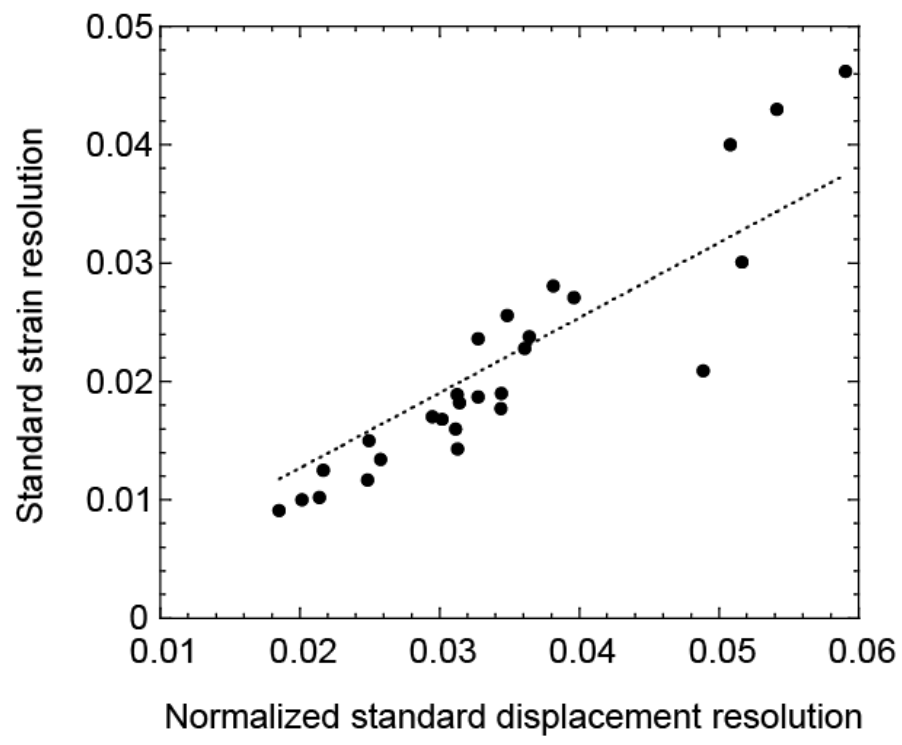

Figure 8: Standard strain resolution as a function of normalized standard displacement resolution for the resolution analysis ( $\ell=16$ voxels). The dashed line corresponds to the prediction of Equation (8) with a constant $\alpha=0.63$.

Up to now, only one element size was considered, namely, $\ell=16$ voxels. In the following analysis, the element size is changed but only one ROI is considered (i.e., ROI2 centre). The three correlation residuals at convergence are found to be virtually identical (to within $0.01 \%)$. This result indicates that the kinematic basis associated with each discretization is able to capture the actual displacement field. The standard displacement resolution as a function of the element size is given in Figure 9. The classical compromise between displacement resolution and element size (proportional to the spatial resolution) is observed, namely, the larger the element size, the smaller 
the displacement resolution. A power law interpolation (lines in Figure 9) is a good approximation of that trade-off.

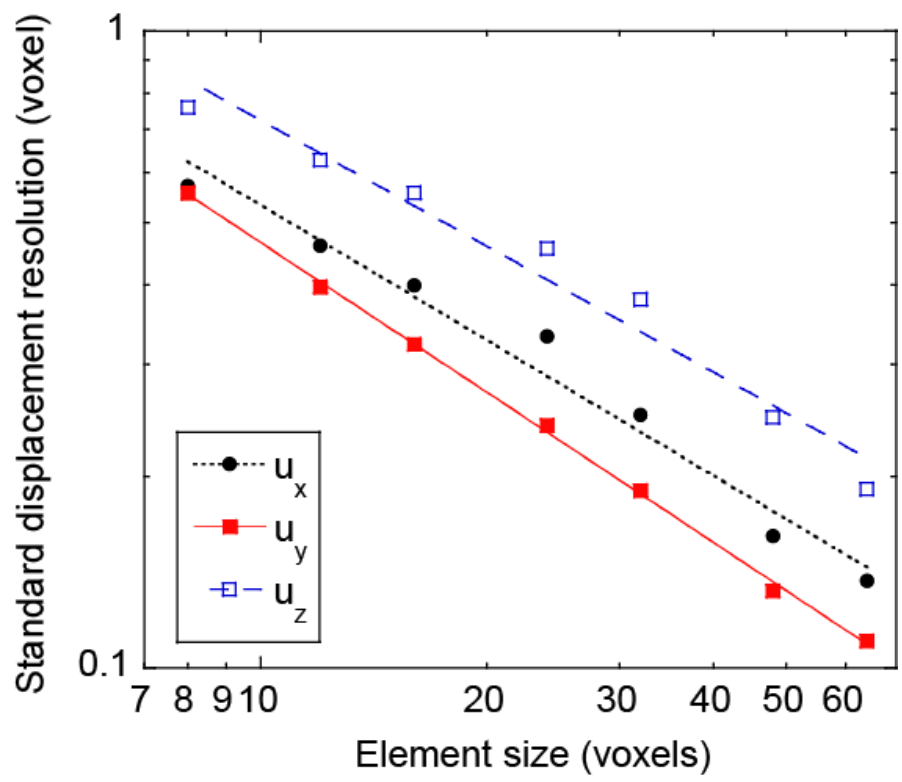

Figure 9: Standard displacement resolution for different element sizes when ROI2 centre Oa is correlated with $\mathrm{ROI} 2$ centre $0 \mathrm{~b}$. The straight lines correspond to power law interpolations of the results.

The change of the standard strain resolution with the element size is shown in Figure 10. It decreases faster with the element size when compared with the displacement resolution (Figure 9). This is to be expected from the result of Equation (8). The compromise between strain resolution and element size is also described by a power law (lines in Figure 10). The levels along the z-direction are systematically higher than those in the other two directions. The reason is identical to what is observed for the displacement resolutions. 


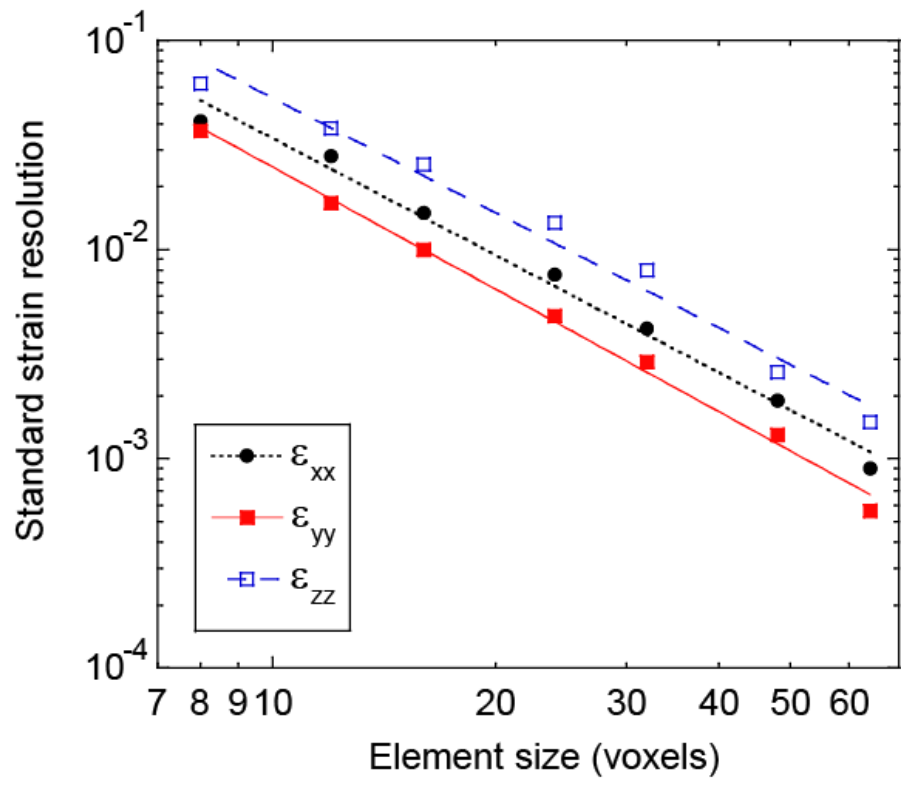

Figure 10: Standard strain resolution for different element sizes when ROI2 centre $0 \mathrm{a}$ is correlated with ROI2 centre Ob. The straight lines correspond to power law interpolations of the results.

In Figure 11, all the previous results are gathered by defining a normalized strain resolution as $\ell \sigma_{\varepsilon} / \sigma_{u}$. For the first six element sizes, a mean value of 0.59 is found. By following the developments of [46], it can be shown that the standard strain resolution of inner nodes of a C8 mesh is related to the standard displacement resolution by $\sigma_{\varepsilon} \approx 0.58 \frac{\sigma_{u}}{\ell}$

This result is in very good agreement with what is observed. 


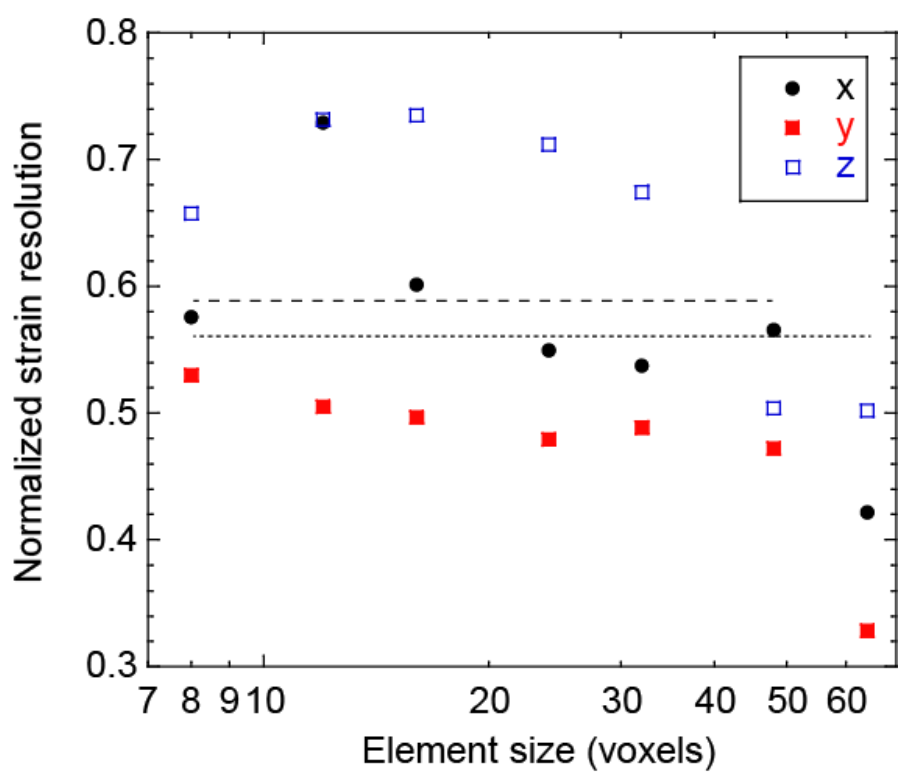

Figure 11: Normalized normal strain resolutions along the three analysed directions vs. element size when ROI2 centre $0 \mathrm{a}$ is correlated with $\mathrm{ROI} 2$ centre $0 \mathrm{~b}$. The dashed lines show average values over 6 or 7 values.

For the largest element size, there is a clear deviation from this analysis. This is due to the fact that there are not so many inner nodes in the chosen ROI. Consequently, the influence of nodes belonging to any external boundary becomes more pronounced. For these nodes the displacement and strain resolutions increase. Their ratio, however, decreases and, for instance, for corner nodes it becomes

$\sigma_{\varepsilon} \approx 0.36 \frac{\sigma_{u}}{\ell}$

The same trend was observed for Q4 elements in 2D-DIC [46]. This effect induces a decrease of the mean normalized strain resolution from 0.59 to 0.56 . Consequently, a first order estimate of the strain resolution, which is an upper bound, is

$\sigma_{\varepsilon} \approx 0.6 \frac{\sigma_{u}}{\ell}$ 
This performance analysis allows us to conclude that displacement fluctuations less than one voxel cannot be assessed with 16-voxel elements. Similarly, strain fluctuations of the order of a few percent and less cannot be captured. If larger elements are chosen (i.e. a coarser mesh), fewer local fluctuations are accessible (e.g. strain localisation). The key point is to use small elements, but not too small. Otherwise the measurement uncertainties will be too high. This is the trade-off the user is faced with (Figures 9 and 10).

\section{Correlation between different loading steps: displacement and strain measurements}

In this part the correlations for scans between different loading steps are performed.

Figure 12 shows 2D sections of reconstructed laminography data at mid thickness for loading step 1 and 3 . The ROI for correlation is indicated on the different sections.

a)

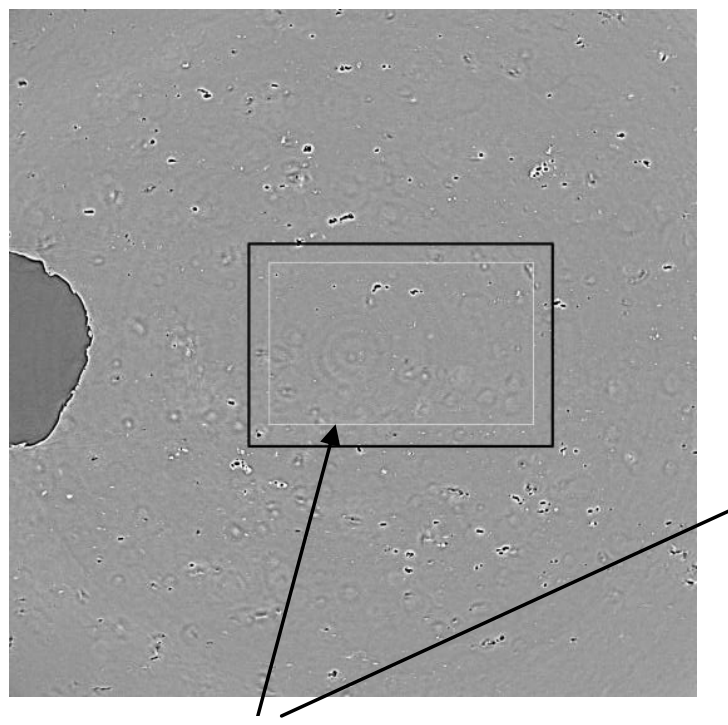

ROI for DVC analvses b)

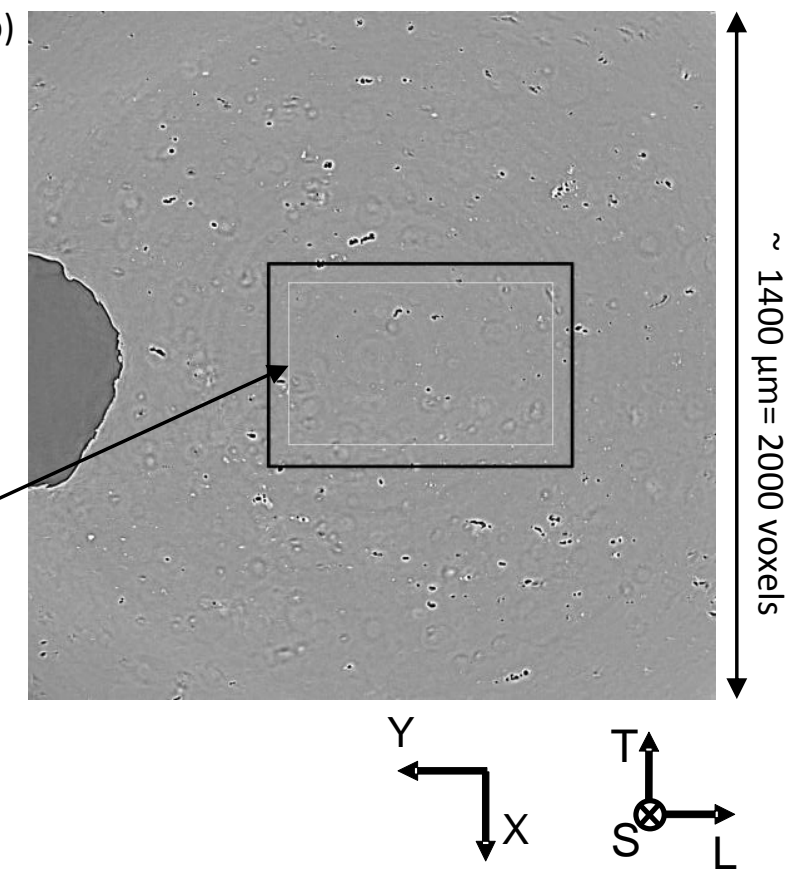

Figure 12: 2D sections of reconstructed laminography data at mid thickness showing the location of the extracted volume (600 × $900 \times 300$ voxels) in black and the ROls $(480 \times 784 \times 176$ voxels) in white for the correlation between the different loading steps a) 1st loading step b) 3rd loading step 


\section{Used parameters}

The correlation analyses have been carried out with an element size of 16 voxels and a convergence criterion of $10^{-4}$ voxel in terms of incremental mean displacements between two successive iterations. This is a good compromise between standard displacement and strain resolutions and the element size (Figures 9 and 10). The numerically extracted volume has a size of $600 \times 900 \times 300$ voxels in which a ROI of $480 \times 784 \times 176$ voxels was used.

\section{Direct Correlations}

Direct correlations (i.e., with no reference update) have been carried out to register the undeformed state directly with the different loading steps. The results are shown in Figure 13. The correlation residuals at convergence slightly increase. The direct correlation between scan $0 \mathrm{~b}$ and scan 3 cannot be carried out without further information as the correlation diverges (i.e., the correlation residuals at convergence did not reach similar levels as for the previous cases). The displacements and the displacement gradients are too large to be determined from a direct correlation with no initialisation. Therefore, updated correlations have been carried out. Furthermore, it is worth noting that the correlation residuals at convergence remain of the same order of magnitude even if the displacements do not remain very small. The fact that a stable value is observed gives confidence in the results obtained in the analyses up to the scan 2. Their level is very close to those observed in the resolution analysis, namely of the order of $4.2 \%$ (Figure 5). Therefore, the results are deemed trustworthy. It can be noted that there is a clear gain when the initial discrepancies are compared with the final ones. It shows that a complex displacement field develops within the sample. This is confirmed by the fact that the discrepancy associated with a rigid body translation remains close to the initial one. 


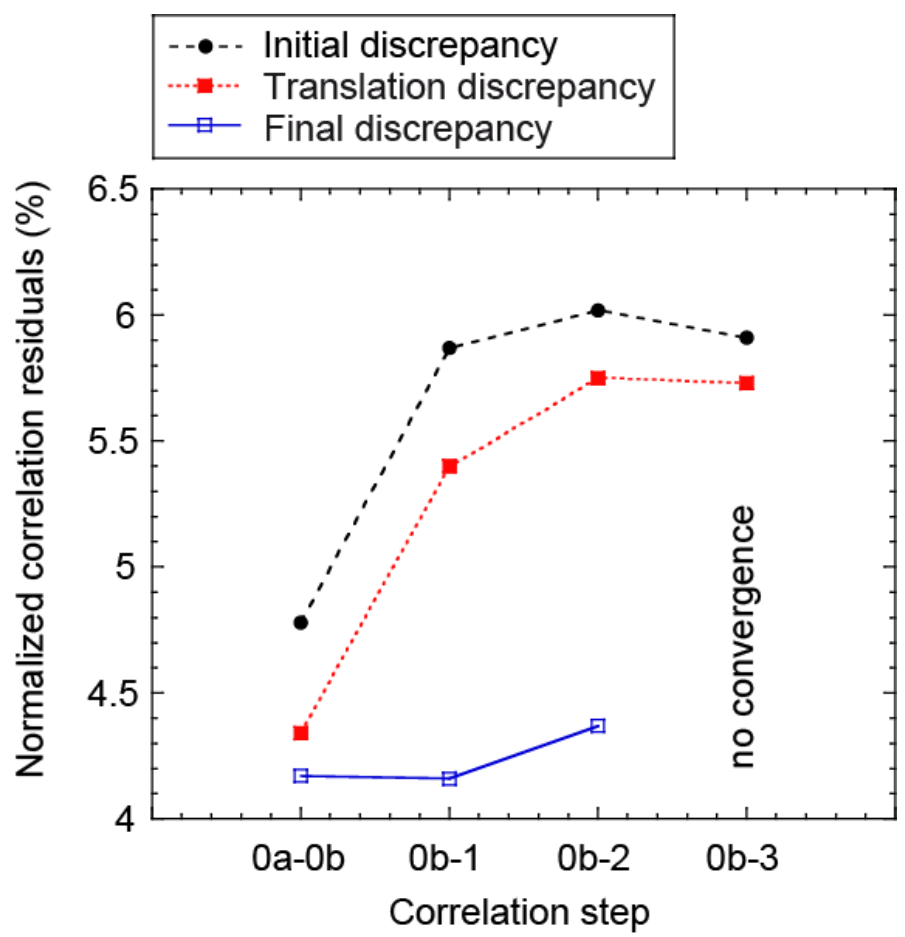

Figure 13: Initial, translated and final discrepancies for different loading steps when no update is performed in the correlation analysis.

\section{Updated Correlations}

Updated correlations as defined above have been carried out successfully. The results of the analyses in terms of correlation residuals are shown in Figure 14. Even though there are large fluctuations of the initial discrepancies and those associated with a rigid body translation correction, the levels at convergence are almost constant for all the analyses and very close to those observed when no mechanical load was applied, namely of the order of $4.2 \%$ (Figure 5). The measured displacement increments are therefore deemed trustworthy. 


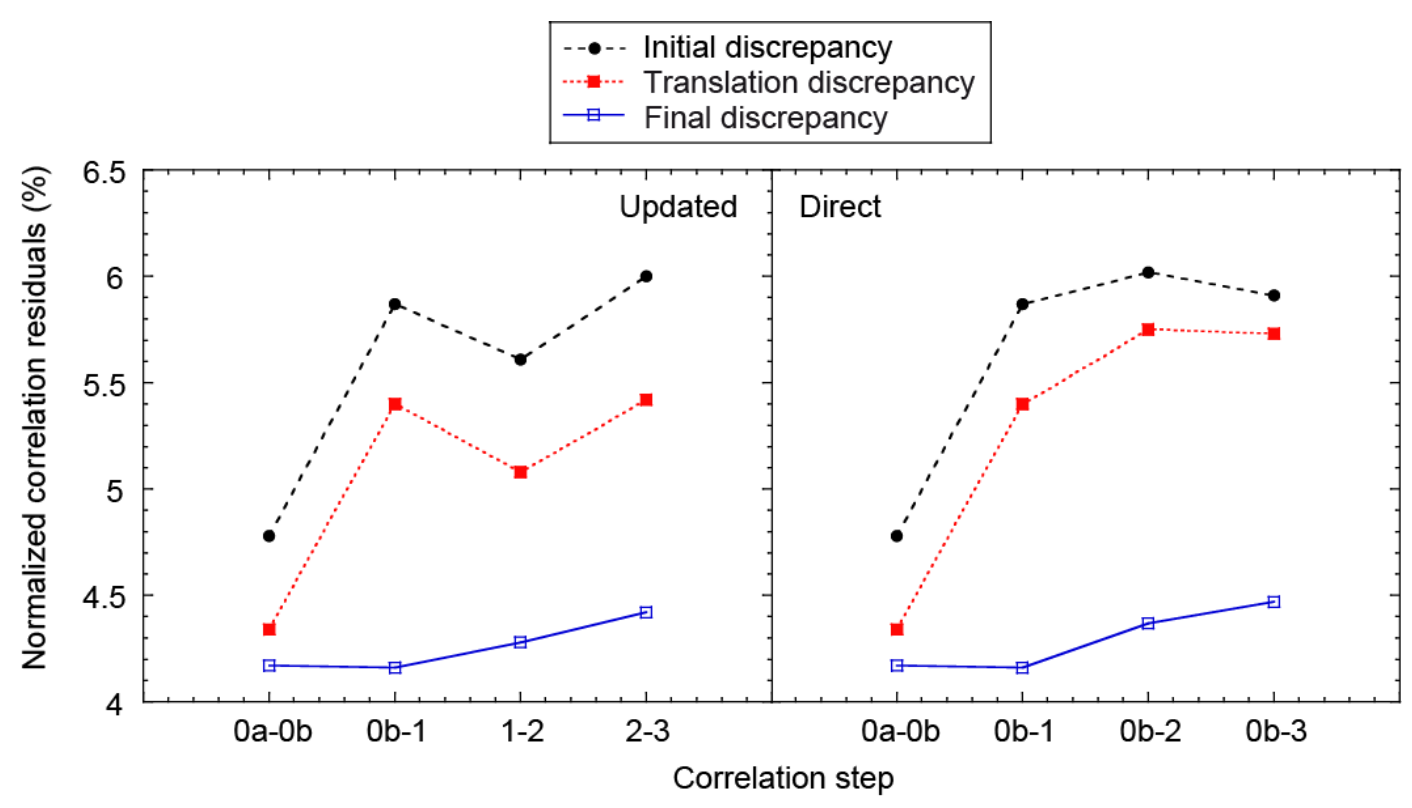

Figure 14: Initial, translated and final discrepancies. On the left: correlation of scans of the undeformed ( $0 \mathrm{a}$ to $\mathrm{Ob}$ ) material and updated correlations between the different loading steps (0b-1, 1-2, 2-3). On the right: same analyses using the cumulated displacement fields obtained in the updated analysis as initial guess.

The results of the updated correlations in terms of displacement field are then cumulated to determine the displacement fields using the undeformed state as the unique reference volume.

\section{Direct Correlation with cumulated updated results as initial guess}

For one of the correlation analyses between the reference state $(0 \mathrm{~b})$ and loading step 3 a direct correlation has been carried out using the cumulated displacement field as an initial guess. The direct correlation without further information was not possible (Figure 13). This direct correlation using supplementary information has been carried out successfully as it can be seen in the following results (Figure 14). It may limit errors in the determination of the displacement field that may occur by cumulating displacement fields from updated correlations. The same is true for loading 2 , even though an update is not needed. 


\section{Residuals}

Figure 14 shows the results in terms of correlation residuals for the scans of the undeformed material as discussed in previous sections and the results of updated correlation, i.e. correlation between loading step $n$ and $n+1$. Initial and translated discrepancies as well as the final discrepancy are shown. Significant fluctuations between the initial discrepancies are seen, which may partly be linked to the manual determination of the position of the reference feature. The discrepancy after translation corrections, however, follows the same trend as the initial discrepancy indicating that most of the differences may actually be due to real relative displacements of the material (i.e. microstructural features) due to the loading resulting in large differences when comparing the images directly.

In addition, the initial and translated discrepancies for the correlation of the scans of the undeformed material are substantially lower than for the correlation between scans of different loading steps. In contrast, the correlation residual at convergence shows very little fluctuation for the different correlations and is always close to the values that have been obtained in the resolution analysis. This result is encouraging as it implies that even for correlations with a high value of initial and translated discrepancies; the value at convergence is close to that induced by the noise that is intrinsic to the technique / the used settings. In other words it implies that the determinations of the displacement field have been performed accurately and that the results are trustworthy.

On the right side of the graph (Figure 14) the results for a direct and initialized correlation are shown. The correlation residuals at convergence are very close to the values observed with an incremental approach, themselves of the same order of magnitude as in the resolution analysis, namely of the order of $4.2 \%$ (Figure 5). The fact 
that they do not deteriorate significantly indicates that accurate results are obtained for large strains. This result validates the new correlation procedure implemented herein.

Figure 15 shows the fields of final discrepancies for the first and third loading steps. For the first loading step, the field is uniform over the whole ROI. This is no longer the case for the third loading step for which void nucleation and possibly void growth/ void shape change may occur. This phenomenon leads to a field that becomes heterogeneous, even though its mean value only slightly increases (Figure 14).
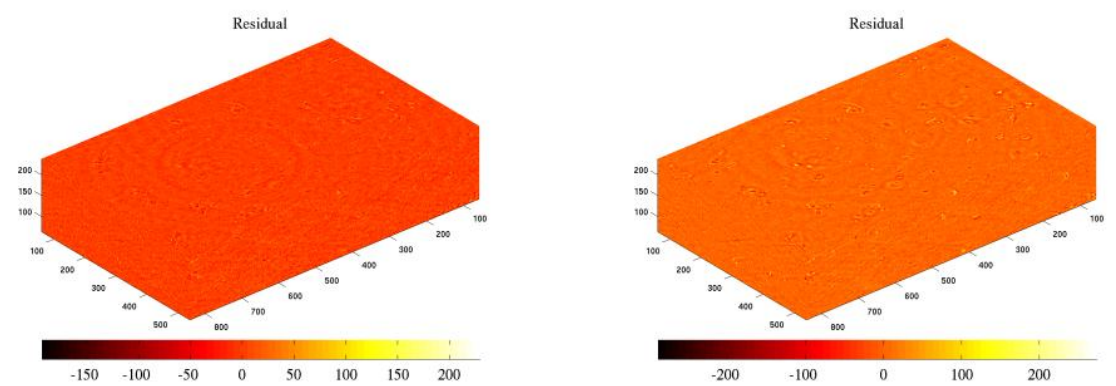

Figure 15: Correlation residual field at convergence (expressed in grey levels) for a direct correlation between scans $0 \mathrm{~b}$ and 1 (left), scans $0 \mathrm{~b}$ and 3 (right), the left side of the box was adjacent to the notch (see Figure 12).

\section{Displacement fields: initial results}

Figure 16 shows correlation results in terms of displacement fields (expressed in $\mu \mathrm{m}$ ) for analyses between the undeformed state with the first loading step, and the undeformed state with the 3rd loading step. Correlation $0 \mathrm{~b}$ to loading step 3 is also a direct analysis using the cumulated displacement field from the updated correlations as an initial guess. The displacement field in $x$-(loading) direction is smooth and consistent with the loading configuration in the $x$-direction, namely, an elongation is detected in this direction. The displacement increases with the loading level (Figure 16b). The displacement gradient in the $x$-direction is more pronounced for the region close to the notch (on the left of the 
block) than for the region that is farther away from the notch (on the right of the block). In the $z$-(through-thickness) direction a contraction of the material is detected, which is also consistent with the loading configuration (Figures $16 \mathrm{c}$ and $\mathrm{d}$ ). The measured contraction is higher close to the notch (on the left, $y=800$ voxels) than farther away from the notch (on the right, $y=0$ ), which is to be expected from stress/strain concentrations close to the notch tip. Some heterogeneity of the displacement field on the left side close to the notch is observed, which will need further analyses to be fully understood. After 3 loading steps, the same features of displacement heterogeneities are observed.

Figures $16 \mathrm{e}$ and $\mathrm{f}$ show the displacement fields in the $y$-(crack propagation) direction. In that direction a contraction of the materials is also measured, which is in line with the loading direction. The magnitude of the displacement in $y$ and $z$ directions is smaller than that in the loading direction, which is consistent with volume conservation associated with plasticity. The displacement amplitudes and the strains being very large along the $z$-direction (Figure 16), updated analyses were necessary because the thickness of the analysed ROI is equal to 176 voxels (i.e., only three coarse-graining steps could be performed). Consequently, for these large displacement and strain amplitudes, an initialisation is needed if a Lagrangian analysis is sought.

Even though the displacement resolution associated with laminography is significantly larger than that observed in $\mathrm{CT}$, it does not bias too much the reported results since the displacement amplitudes are at least one order of magnitude larger. The same conclusion would not have been possible had the behaviour of the studied material remained elastic. 
Scan 1 / scan 0 b

(a)

(c)

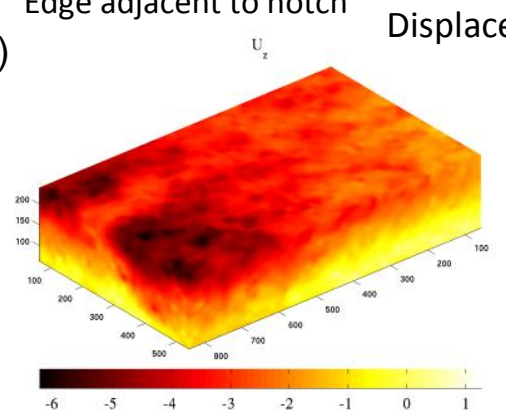

(b)

\section{Scan 3 / scan Ob}

Displacement field in $x$-direction in $\mu \mathrm{m}$

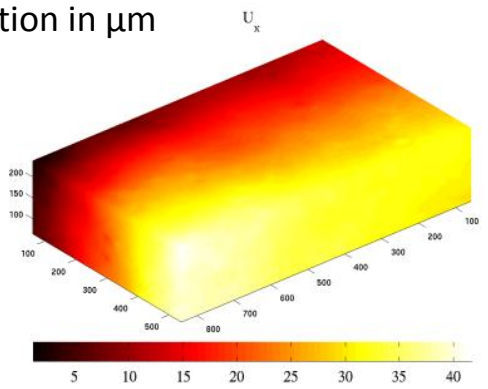

Displacement field in $y$-direction in $\mu \mathrm{m}$

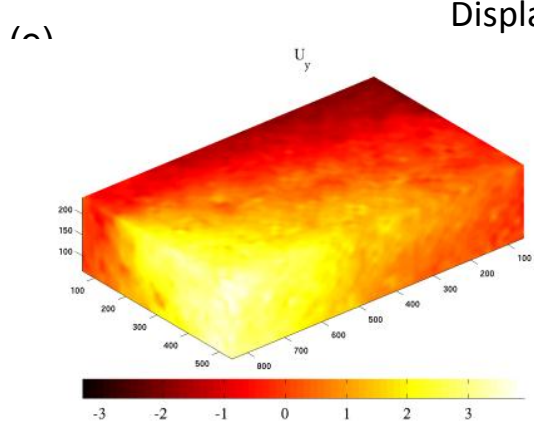

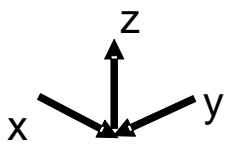

(d)

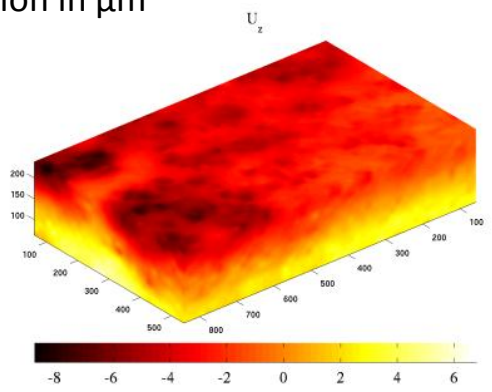

(f)

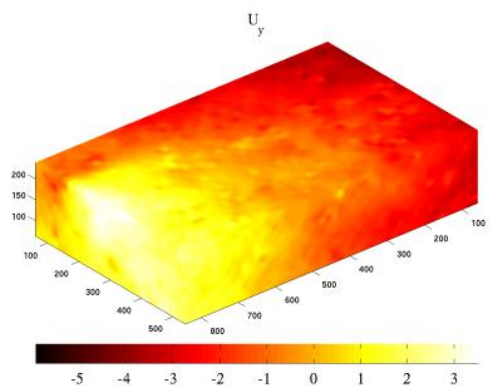

Figure 16: 3D Displacement fields (expressed in $\mu \mathrm{m}$, in a volume of $480 \times 784 \times$

176 voxels $\hat{=} 336 \mu \mathrm{m} \times 549 \mu \mathrm{m} \times 123 \mu \mathrm{m}$ ) for direct correlation between scans 0b with 1 , and $0 \mathrm{~b}$ with 3 respectively for: $\mathrm{a}$ ) and b) displacement field in $x$-(loading) direction, $c$ ) and d) displacement field in z-(though thickness) direction, e) and f) displacement fields in $y$-(crack propagation) direction, the left side of the box was adjacent to the notch (see Figure 12).

\section{Strain fields: initial results}

Figures $17 \mathrm{a}$,b show normal strain fields ( $\varepsilon_{\mathrm{xx}}$ in loading direction) that have been derived from the displacement fields for correlation between the undeformed material and 
loading step 1 and the undeformed material and loading step 3. A gradient in strain is seen from the location close to the notch (on the left) to the location farther away from the notch and at mid height, which is consistent with the stress / strain concentration in the vicinity of the notch. The strain field is more heterogeneous than the displacement field. In some locations high strain levels are located next to low strain levels. Further assessment will be needed to clarify the exact origin of these heterogeneities. With increasing load the strain level also increases. It is believed that the origin of strain heterogeneities are mainly related to plasticity and not to measurement uncertainties since their order of magnitude is significantly higher than the latter ones (i.e., of the order of 0.01 , Figure 10). Additional scans related to larger CMODs need to be analysed to confirm this hypothesis.

\section{Scan 1 / scan Ob}

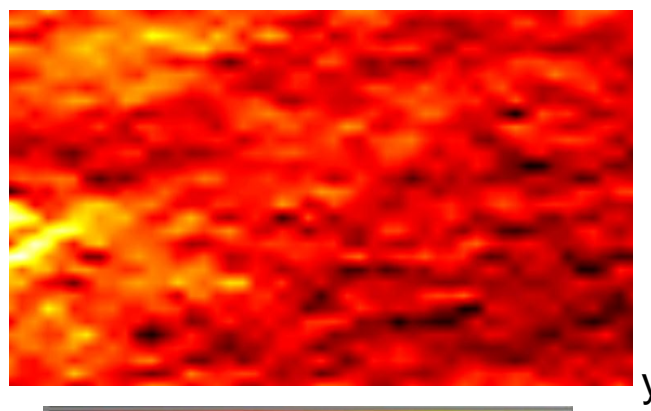

Min: 0.0 $\varepsilon_{\mathrm{xx}}$

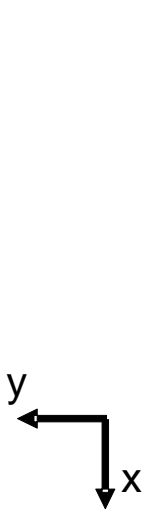

\section{Scan 3 / scan Ob}

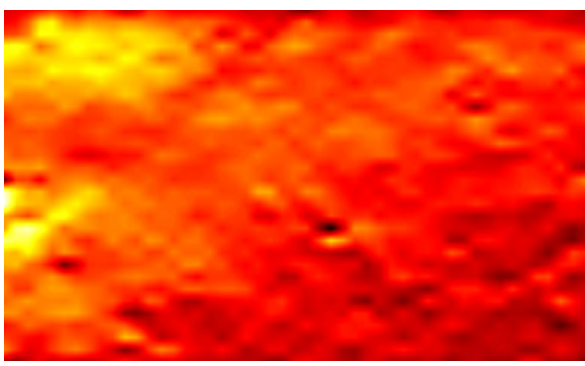

Min: 0.0

Max: 0.31

Figure 17: 2D section of the strain fields (field size $464 \times 768 \times 160$ voxels $\hat{=} 325 \mu \mathrm{m} \times$

$538 \mu \mathrm{m} \times 112 \mu \mathrm{m}$ ) for $\varepsilon_{\mathrm{xx}}$ strain at the mid-thickness of the ROI for direct correlations

between: a) Scan $0 \mathrm{~b}$ and 1, b) Scan $0 \mathrm{~b}$ and 3 (the cumulated displacement field from updated correlations has been used as an initial guess).

\section{Discussion}

In this paper, an initial assessment of the feasibility of displacement and strain field measurements using DVC of laminography data of ductile crack initiation in an industrial 
Al-alloy has been conducted. It shows promising results even though the measurement resolution is not equivalent to what is observed with computed tomography data. The influence of the noise / experimental conditions on the displacement resolution and strain resolution was analysed. The influence of the shift of the rotation axis between the different scans has been assessed. It leads to displacement resolutions in the decivoxel range, and strain resolutions of the order of $1 \%$ for 16 -voxel C8 elements. These values were obtained for the studied material (i.e., with a very small content of microstructural markers) and are not necessarily generic for laminography. This point needs more analyses with different materials exhibiting different microstructural features (e.g., different void / particle volume fractions).

For the particular case of ductile fracture the influence of damage evolution on the correlation residuals should be assessed further to identify the strain/damage state up to which a measurement can be made. From a material science and fracture mechanics point of view, there is a vast amount of data to be gathered once the measurement technique is validated. For instance, the actual strain fields during crack initiation can be measured and interactions between damage and strain fields assessed in more details. These measurements can then be compared to FE modelling results.

\section{Conclusions}

In this study, synchrotron laminography has been used in combination with digital volume correlation (DVC) to measure displacement fields during ductile crack initiation in a commercial Al alloy. Synchrotron laminography is a technique particularly adapted to study objects that are extended in two directions and thin in the third one at a micrometre resolution. This represents a major advantage over computed tomography when the crack initiation and propagation in sheet material is to be studied since using laminography boundary conditions closer to engineering applications can be applied. 
The contrast used to determine displacement fields is natural, namely, due to initial porosity and intermetallic particles present in the material at a very small volume fraction.

A first resolution assessment of the measurement of 3D displacement and strain fields has been performed using scans without applying any load to the specimen. The effect of a shift of the rotation axis (with respect to the specimen) of the scan on correlation residuals for the undeformed material has been carried out for a value of more than half the size of the reconstructed volume. The correlation residuals for different regions within the scan have been carried out showing that the best correlation results in terms of measurement uncertainty is obtained for zones that are contained in a radius of $\sim 0.7 \mathrm{~mm}$ from the scan rotation axis for both scans. The effect of element size on measurement resolution has been performed showing poorer resolutions than for computed tomography, yet sufficient to analyse kinematic fields associated with plasticity.

For the correlation of the scan of the material between different loading steps, various analyses have been performed:

- The different correlation residuals have been calculated for the updated analyses. The residual at convergence is similar to that obtained for the correlation of undeformed material scans, thereby indicating that the incremental correlation results are trustworthy.

- Direct correlations between loading steps that are distant from each other could be obtained using the cumulated displacement field as an initial guess have been carried out for the first time. The residual at convergence is close to the results of the updated correlations and the correlation of scans of the undeformed material. This result indicates that the procedure yields trustworthy results. 
- The measured displacement fields are in agreement with the loading configuration showing elongation for one direction and contraction along the 2 others. There is a gradient in displacement in the region close to the notch to the region farther away from the notch, which is consistent with the stress / strain concentrations expected to occur around the notch tip.

- The strain field shows heterogeneous values that are higher close to the notch than farther away.

\section{Acknowledgements}

The authors would like to acknowledge lan Sinclair and Mark Mavrogordato from the University of Southampton for participating in/ helping with the laminography experiment. Feng $\mathrm{Xu}$ is thanked for help with reconstruction of the data. Thibault Taillandier-Thomas is also thanked for running some resolution assessments.

\section{References}

[1] Zerbst U, Heinimann M, Dalle Donne C, Steglich D. Fracture and damage mechanics modelling of thin-walled structures. An overview. Eng. Fract. Mech. 2009;76:5-43.

[2] Chen J, Madi Y, Morgeneyer TF, Besson J. Plastic flow and ductile rupture of a $2198 \mathrm{Al}-$ Cu-Li aluminium alloy. Comp. Mat. Sci. 2011;50:1365-1371.

[3] Le Jolu T, Morgeneyer TF, Gourgues-Lorenzon A-F. Effect of joint line remnant on fatigue lifetime of friction stir welded Al-Cu-Li alloy. Sci. Tech. of Weld. Joining 2010;15:694-698.

[4] Mahgoub E, Deng X, Sutton MA. Three dimensional stress and deformation fields around flat and slant cracks under remote mode I loading conditions. Eng. Fract. Mech. 2003;70:2527-2542.

[5] Lorthios J, Nguyen F, Gourgues-Lorenzon A-F, Morgeneyer TF, Cugy P. Damage observation in a high manganese austenitic Twinning Induced Plasticity (TWIP) steel by synchrotron radiation computed tomography. Scripta Mat. 2010;63:1220-1223.

[6] Morgeneyer TF, Besson J. Flat to slant ductile fracture transition: tomography examination and simulations using shear controlled void nucleation. Scripta Mat. 2011;65:1002-1005.

[7] Maire E, Zhou S, Adrien J, Dimichiel M. Damage quantification in aluminium alloys using in situ tensile tests in X-ray tomography. Eng. Fract. Mech. 2011;78:2679-2690.

[8] Landron C, Bouaziz O, Maire E, Adrien J. Characterization and modeling of void nucleation by interface decohesion in dual phase steels. Scripta Mat. 2010;63:973-976.

[9] Maire E, Morgeneyer TF, Landron C, Adrien J, Helfen L. Bulk evaluation of ductile damage development using high resolution tomography and laminography. C. $R$. Physique 2012;13:328-336. 
[10] Helfen L, Myagotin A, Mikulík P, Pernot P, Voropaev A, Elyyan M, Di Michiel M, Baruchel $\mathrm{J}$, Baumbach T. On the implementation of computed laminography using synchrotron radiation. Rev. Sci. Instrum. 2011;82.

[11] Helfen L, Morgeneyer TF, Xu F, Mavrogordato MN, Sinclair I, Schillinger B, Baumbach T. Synchrotron and neutron laminography for three-dimensional imaging of devices and flat material specimens. Int. J. Mat. Res. 2012;2012:170-173.

[12] Maurel V, Helfen L, N'Guyen F, Köster A, Di Michiel M, Baumbach T, Morgeneyer TF. Three-dimensional investigation of thermal barrier coatings by synchrotron-radiation computed laminography. Scripta Mat. 2012; 66:471-474.

[13] Moffat AJ, Wright P, Helfen L, Baumbach T, Johnson G, Spearing SM, Sinclair I. In situ synchrotron computed laminography of damage in carbon fibre-epoxy [90/0]s laminates. Scripta Mat. 2010;62:97-100.

[14] Morgeneyer TF, Helfen L, Sinclair I, Proudhon H, Xu F, Baumbach T. Ductile crack initiation and propagation assessed via in situ synchrotron radiation computed laminography. Scripta Mat. 2011;65:1010-1013.

[15] Sutton MA, Orteu J-J, Schreier H. Image correlation for shape, motion and deformation measurements: Basic Concepts, Theory and Applications. Springer; 2009.

[16] Bay BK, Smith TS, Fyhrie DP, Saad M. Digital volume correlation: three-dimensional strain mapping using X-ray tomography. Exp. Mech. 1999;39:217-226.

[17] Smith TS, Bay BK, Rashid MM. Digital volume correlation including rotational degrees of freedom during minimization. Exp. Mech. 2002;42:272-278.

[18] Bornert M, Chaix J-M, Doumalin P, Dupré J-C, Fournel T, Jeulin D, Maire E, Moreaud M, Moulinec $\mathrm{H}$. Mesure tridimensionnelle de champs cinématiques par imagerie volumique pour l'analyse des matériaux et des structures. Inst. Mes. Métrol. 2004;4:43-88.

[19] Verhulp E, van Rietbergen B, Huiskes R. A three-dimensional digital image correlation technique for strain measurements in microstructures. J. Biomech. 2004;37:1313-1320.

[20] Liu L, Morgan E. Accuracy and precision of digital volume correlation in quantifying displacements and strains in trabecular bone. J. Biomech. 2007;40:3516-3520.

[21] Forsberg F, Mooser R, Arnold M, Hack E, Wyss P. 3D micro-scale deformations of wood in bending: Synchrotron radiation $\mu \mathrm{CT}$ data analyzed with digital volume correlation. $J$. Struct. Biol. 2008;164:255-262.

[22] Nielsen SF, Poulsen HF, Beckmann F, Thorning C, Wert JA. Measurements of plastic displacement gradient components in three dimensions using marker particles and synchrotron X-ray absorption microtomography. Acta Mater. 2003;51:2407-2415.

[23] Limodin N, Réthoré J, Buffière J-Y, Gravouil A, Hild F, Roux S. Crack closure and stress intensity factor measurements in nodular graphite cast iron using 3D correlation of laboratory X ray microtomography images. Acta Mat. 2009;57:4090-4101.

[24] Roux S, Hild F, Viot P, Bernard D. Three dimensional image correlation from X-Ray computed tomography of solid foam. Comp. Part A 2008;39:1253-1265.

[25] Réthoré J, Tinnes J-P, Roux S, Buffière J-Y, Hild F. Extended three-dimensional digital image correlation (X3D-DIC). C. R. Mecanique 2008;336:643-649.

[26] Rannou J, Limodin N, Réthoré J, Gravouil A, Ludwig W, Baïetto M-C, Buffière J-Y, Combescure A, Hild F, Roux S. Three dimensional experimental and numerical multiscale analysis of a fatigue crack. Comp. Meth. Appl. Mech. Eng. 2010;199:1307-1325.

[27] Limodin N, Réthoré J, Buffière J-Y, Hild F, Roux S, Ludwig W, Rannou J, Gravouil A. Influence of closure on the 3D propagation of fatigue cracks in a nodular cast iron investigated by X-ray tomography and 3D Volume Correlation. Acta Mat. 2010;58:29572967.

[28] Morgeneyer TF, Besson J, Proudhon H, Starink MJ, Sinclair I. Experimental and numerical analysis of toughness anisotropy in AA2139 Al-alloy sheet. Acta Mat. 2009;57:39023915.

[29] Helfen L, Baumbach T, Mikulík P, Kiel D, Pernot P, Cloetens P, Baruchel J. High-resolution three-dimensional imaging of flat objects by synchrotron-radiation computed laminography. Appl. Phys. Lett. 2005;86.

[30] Helfen L, Myagotin A, Rack A, Pernot P, Mikulík P, Di Michiel M, Baumbach T. Synchrotron-radiation computed laminography for high-resolution three-dimensional imaging of flat devices. Phys. Stat. Sol. (a) 2007;204:2760-2765. 
[31] Xu F, Helfen L, Baumbach T, Suhonen H. Comparison of image quality in computed laminography and tomography. Optics Express 2012;20:794-806.

[32] Helfen L, Baumbach T, Cloetens P, Baruchel J. Phase contrast and holographic computed laminography. Appl. Phys. Lett. 2009;94.

[33] Xu F, Helfen L, Moffat AJ, Johnson G, Sinclair I, Baumbach T. Synchrotron radiation computed laminography for polymer composite failure studies. J. Synchr. Radiat. 2010;17:222-226.

[34] Harasse S, Hirayama N, Yashiro W, Momose A. X-ray phase laminography with Talbot interferometer. Proc. SPIE 2010;7804.

[35] Altapova V, Helfen L, Myagotin A, Hänschke D, Moosmann J, Gunneweg J, Baumbach T. Phase contrast laminography based on Talbot interferometry. Optics Express 2012;20:6496-6508.

[36] Krug K, Porra L, Coan P, Wallert A, Dik J, Coerdt A, Bravin A, Elyyan M, Reischig P, Helfen $L$, Baumbach T. Relics in medieval altarpieces? Combining $X$ ray tomographic, laminographic and phase contrast imaging to visualize thin organic objects. J. Synchr. Radiat. 2008;15:55-61.

[37] Weitkamp T, Tafforeau P, Boller E, Cloetens P, Valade J-P, Bernard P, Peyrin F, Ludwig W, Helfen L, Baruchel J. Status and evolution of the ESRF beamline ID19. In. ICXOM 2009, AIP Conf. Proc.; 2010.

[38] Rack A, Weitkamp T, Riotte M, Grigoriev D, Rack T, Helfen L, Baumbach T, Dietsch R, Holz T, Krämer M, Siewert F, Meduna M, Cloetens P, Ziegler E. Comparative study of multilayers used in monochromators for synchrotron-based coherent hard X-ray imaging. J. Synchr. Radiat. 2010;17:496-510.

[39] Sijbers J, Postnovz A. Reduction of ring artefacts in high resolution micro-CT reconstructions. Phys. Med. Biol. 2004;49:247-253.

[40] Cloetens P, Pateyron-Salomé M, Buffière J-Y, Peix G, Baruchel J, Peyrin F, Schlenker M. Observation of microstructure and damage in materials by phase sensitive radiography and tomography J. Appl. Phys. 1997;81.

[41] Zienkievicz OC, Taylor RL. The Finite Element Method. McGraw-Hill; 1989.

[42] 99-12:2007 IIg. International Vocabulary of Metrology - Basic and General Concepts and Associated Terms, VIM. International Organization for Standardization; 2007.

[43] Hild F, Maire E, Roux S, Witz J-F. Three dimensional analysis of a compression test on stone wool. Acta Mat. 2009;57:3310-3320.

[44] Limodin N, Réthoré J, Adrien J, Buffière J-Y, Hild F, Roux S. Analysis and artifact correction for volume correlation measurements using tomographic images from a laboratory X-ray source. Exp. Mech. 2011;51:959-970.

[45] Leclerc H, Périé J-N, Hild F, Roux S. Digital Volume Correlation: What are the limits to the spatial resolution? 2012.

[46] Hild F, Roux S. Comparison of local and global approaches to digital image correlation. Exp. Mech. 2012. 